\title{
Isolated zero-voltage switching two-inductor boost converter with two coupled input inductors and one magnetic core *
}

\author{
P Wolfs ${ }^{\dagger}$ and Q Li \\ Central Queensland University, Rockhampton, Queensland, Australia
}

\begin{abstract}
SUMMARY: The isolated two-inductor boost converter with an auxiliary transformer has been previously proposed for applications where the low voltage inputs need to be transformed to high voltage outputs. In order to utilise the leakage inductance of the isolation transformer, the zero-voltage switching (ZVS) topology can be employed. However, a large component count exists in the resonant converter and this contributes to cost and size. In this paper, a new ZVS isolated two-inductor boost converter with two coupled input inductors and an integrated magnetic structure is proposed. In the proposed topology, the seven copper windings and the five magnetic cores required by the auxiliary transformer, the two input inductors, the resonant inductor and the isolation transformer in the discrete magnetic arrangement are integrated into one magnetic core with four copper windings. This paper establishes the inherent relationship between the integrated and the discrete magnetic implementations of the isolated ZVS two-inductor boost converter with two coupled input inductors through the switching state and magnetic circuit analyses. This significantly simplifies the analysis of the new converter with the magnetic integration by modelling the converter with its discrete magnetic equivalent. Finally, both the theoretical and the experimental waveforms of a $1 \mathrm{MHz} 100 \mathrm{~W}$ converter are provided and they agree well with each other.
\end{abstract}

\section{INTRODUCTION}

The isolated two-inductor boost converter with an auxiliary transformer has been previously developed by introducing an additional auto transformer to the original two-inductor boost converter (Wolfs, 1993; Jang \& Jovanovic, 2001; 2002; Jang et al, 2005). In this converter, the auxiliary transformer has a unity turns ratio and couples the two currents in the two input inductors (Jang \& Jovanovic, 2001; 2002). This topology is suitable for the applications such as uninterrupted power supplies and grid interactive photovoltaic (PV) converters, where a large difference between the input and the output voltages exists.

In the hardware design of the isolated two-inductor boost converter with an auxiliary transformer, a significant barrier to increasing the switching frequency is the leakage inductance of the isolation

* Paper originally presented at the 2008 Australasian Universities Power Engineering Conference (AUPEC08), Sydney, NSW, 14-17 December 2008.

+ Corresponding author Prof Peter Wolfs can be contacted at p.wolfs@curtin.edu.au. transformer as it causes severe voltage ringing on the two primary switches (Jang \& Jovanovic, 2002). In the hard switched operation, higher than normal voltage stresses exist on the two primary switches and the energy stored in the transformer leakage inductance is dissipated in the primary switches. Therefore reasonable converter efficiencies cannot be maintained under high frequency operations. One possible solution is to create a resonant tank in the converter to actively utilise the leakage inductance of the isolation transformer (Wolfs \& Li, 2002). This results in the isolated zero-voltage switching (ZVS) two-inductor boost converter with an auxiliary transformer as shown in figure 1.

The hardware implementation of the isolated ZVS two-inductor boost converter with an auxiliary transformer, however, does require a large component count especially due to the requirement of five separate magnetic components. Seven copper windings and five magnetic cores are used in the converter, which are accounted for the bulk, weight and cost (Bloom, 2003). Since the auxiliary transformer in the converter shown in figure 1 couples the two input inductors, a variation can be developed as shown in figure 2, where a direct coupling is produced between the two 


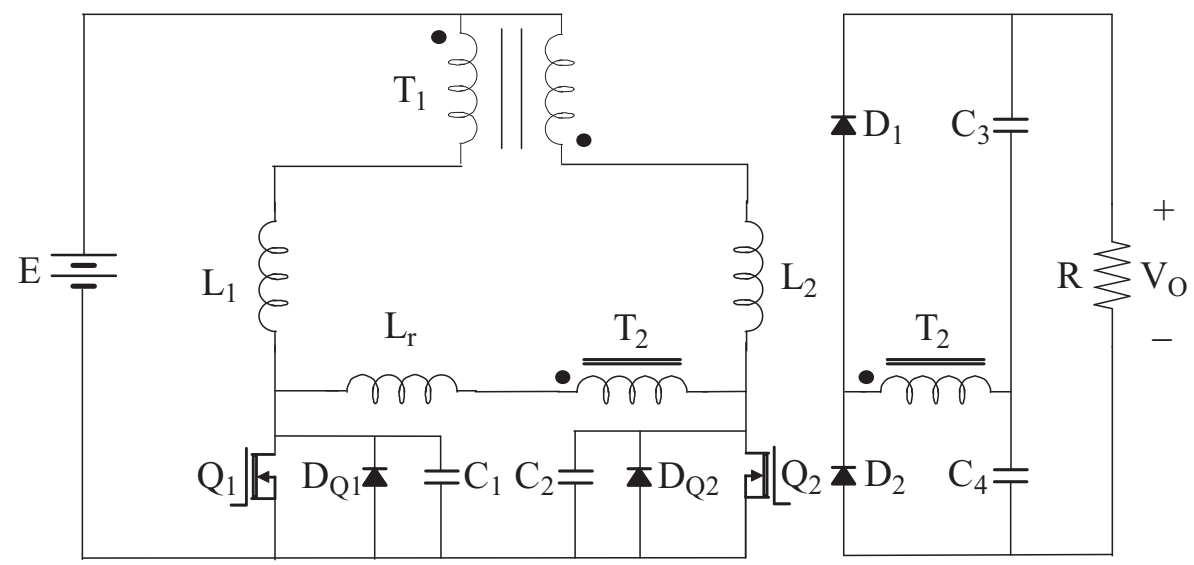

Figure 1: Isolated ZVS two-inductor boost converter with an auxiliary transformer and discrete magnetic structures.

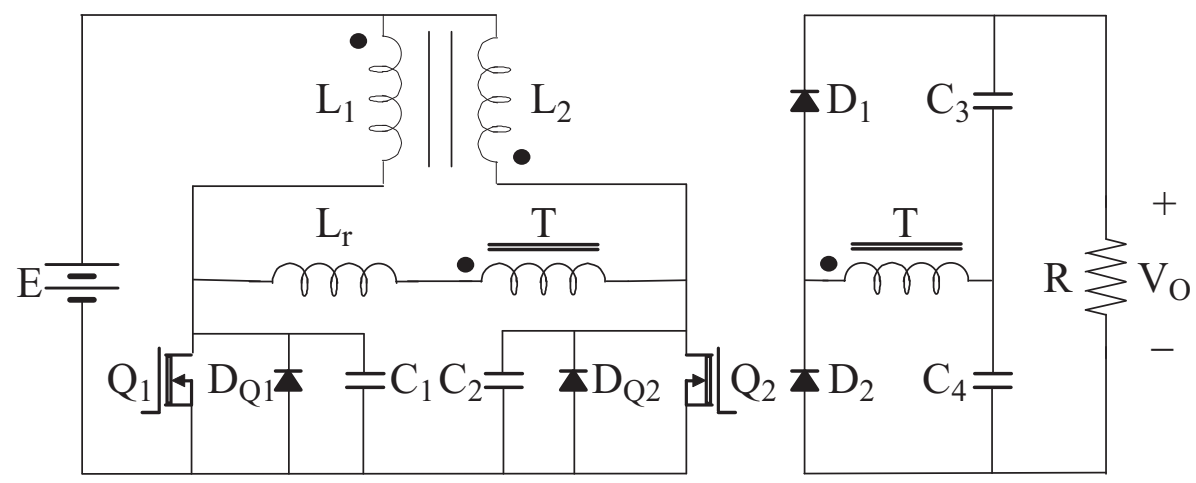

Figure 2: Isolated ZVS two-inductor boost converter with two coupled input inductors and discrete magnetic structures.

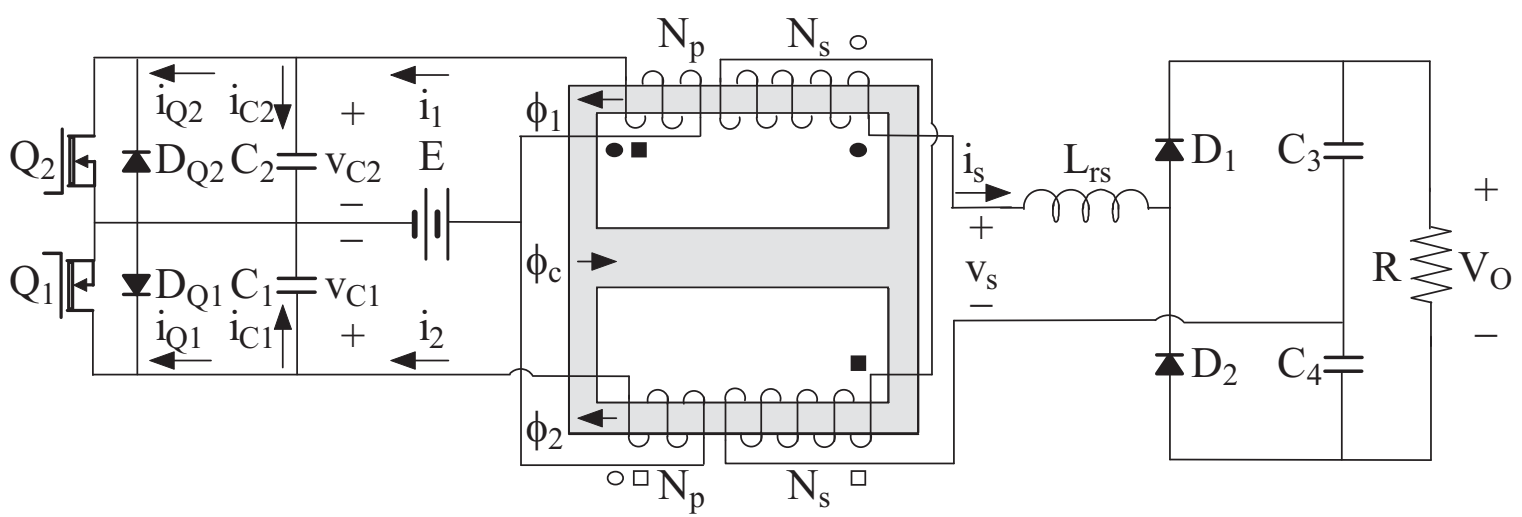

Figure 3: Isolated ZVS two-inductor boost converter with two coupled input inductors and an integrated magnetic structure.

input inductors. An integrated magnetic structure has been previously proposed for the hard-switched converter with two coupled input inductors (Yan \& Lehman, 2003; 2005; Gao \& Ayyannar, 2004; Li \& Wolfs, 2005a). In that structure, both magnetic core and winding integration technologies are employed (Bloom \& Severns, 1984; Chen, 1998).

This paper proposes the magnetic integration for the isolated ZVS two-inductor boost converter with two coupled input inductors as shown in figure 3. In this new topology, the resonant inductor is purely realised by the transformer leakage inductance and the five separate magnetic devices are integrated into four copper windings on a single magnetic core. Therefore, both the component count and the interconnections between the copper windings can be significantly reduced. Through the analyses of the switching states and the magnetic circuits, it is confirmed that the operation of the ZVS converter with the integrated magnetics can be fully established by investigating its equivalent circuit model with the discrete magnetics. Both the theoretical and the experimental waveforms of a $1 \mathrm{MHz} 100 \mathrm{~W}$ converter are provided at the end of the paper to verify the theoretical analysis. 


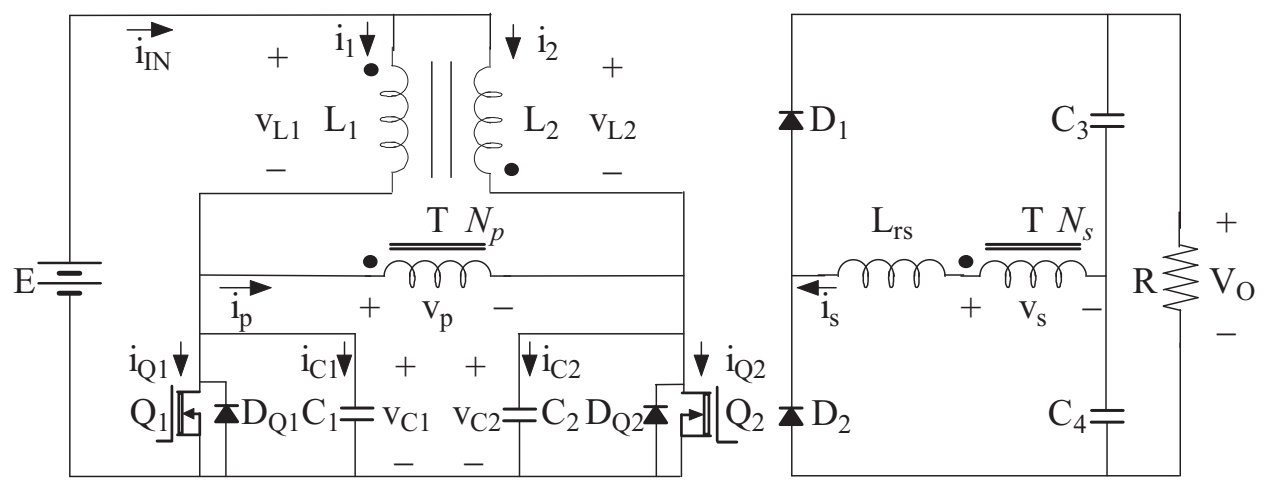

Figure 4: Isolated ZVS two-inductor boost converter with the resonant inductor relocated to the transformer secondary side.

\section{ISOLATED ZVS TWO-INDUCTOR BOOST CONVERTER WITH TWO COUPLED INPUT INDUCTORS AND DISCRETE MAGNETIC STRUCTURES}

In figure 3, the two windings on the converter primary side are employed as both the input inductor and the transformer primary windings. This arrangement presents significant difficulties to the converter analysis. In order to simplify the analysis of the converter with an integrated magnetic structure shown in figure 3 , its equivalent model with a discrete magnetic structure must be first established. Therefore, the switching states of the converter with discrete magnetics shown in figure 2 will be analysed. To be consistent with the topology shown in figure 3 , the resonant inductance is relocated to be in series with the transformer secondary winding as shown in figure 4 . In figure $4, L_{1}=L_{2}=L$ is the input inductance, $C_{1}=C_{2}=C_{r}$ is the resonant capacitance, $L_{r s}$ is the resonant inductance referred to the transformer secondary side, and $N_{p}$ and $N_{s}$ are, respectively, the numbers of turns of the transformer primary and secondary windings.

The converter shown in figure 4 will go through four switching states in one switching period. Assume that $L_{m s}$ is the transformer magnetising inductance referred to the secondary side, the derivatives of the converter instantaneous input and transformer secondary currents can be obtained as follows (Li \& Wolfs, 2005b):

$$
\begin{aligned}
& \frac{d\left(i_{1}+i_{2}\right)}{d t}=\frac{1}{L}\left(2 E+K_{1} \frac{N_{p}}{N_{s}} v_{s}\right) \\
& \frac{d i_{s}}{d t}=K_{2} \frac{N_{p}}{N_{s}} \cdot \frac{E}{L}-\left[\frac{1}{L_{m s}}+\left(\frac{N_{p}}{N_{s}}\right)^{2} \frac{1}{L}\right] v_{s}-\left(\frac{N_{p}}{N_{s}}\right)^{2} C_{r} \frac{d^{2} v_{s}}{d t^{2}}
\end{aligned}
$$$$
\frac{d\left(i_{1}+i_{2}\right)}{d t}=\frac{2 E}{L}
$$

$$
\frac{d i_{s}}{d t}=K_{3} \frac{V_{O}}{2 L_{r s}}
$$

In equations (1) to (4), the coefficient $K_{j}= \pm 1$ depending on the specific switching state, where $j=1,2$, 3. In State $1, Q_{1}$ is off and $Q_{2}$ is on. The current derivatives can be described by equations (1) and (2), where $K_{1}=-1$ and $K_{2}=+1$.

In State 2, $Q_{1}$ and $Q_{2}$ are both on. The current derivatives can be described by equations (3) and (4), where $K_{3}=-1$. In State $3, Q_{1}$ is on and $Q_{2}$ is off. The current derivatives can be described by equations (1) and (2), where $K_{1}=+1$ and $K_{2}=-1$. In State $4, Q_{1}$ and $Q_{2}$ are both on. The current derivatives can be described by equations (3) and (4), where $K_{3}=+1$.

\section{MAGNETIC INTEGRATION ANALYSIS}

In this section, the magnetic circuit of the integrated magnetic structure shown in figure 3 will be analysed in order to obtain the equivalent input and the magnetising inductances of the isolated ZVS two-inductor boost converter with the magnetic integration.

The magnetic circuit of the integrated magnetic structure shown in figure 3 is shown in figure 5, where $\Re_{o}$ and $\Re_{c}$ are, respectively, the reluctances of the outer and centre core legs, and $\phi_{1}, \phi_{2}$ and $\phi_{c}$ are, respectively, the instantaneous fluxes in the individual core legs. The magnetic circuit is valid for the entire switching period due to the existence

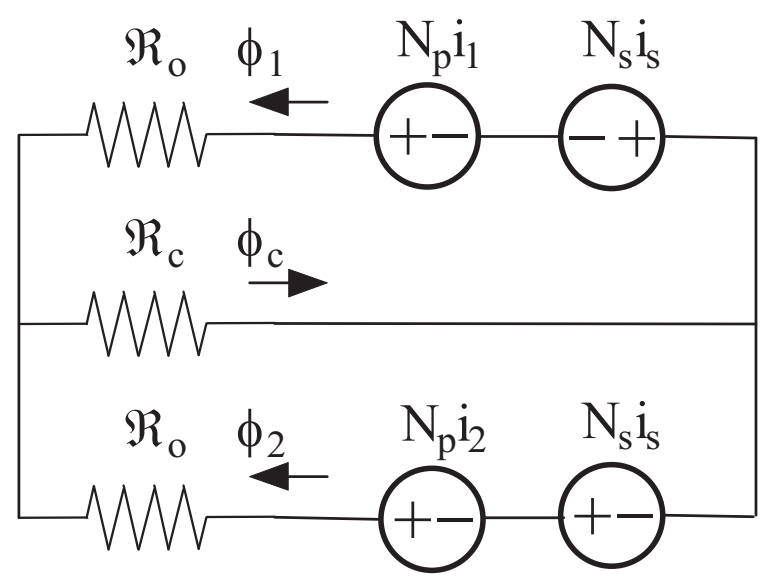

Figure 5: Magnetic circuit. 
of the resonant capacitors $C_{1}$ and $C_{2}$. According to Kirchhoff's current law (KCL), the fluxes in the individual core legs can be calculated as:

$$
\begin{aligned}
& \phi_{1}=\frac{N_{p} i_{1}}{\mathfrak{R}_{o}+2 \mathfrak{R}_{c}}\left(1+\frac{\mathfrak{R}_{c}}{\mathfrak{R}_{o}}\right)-\frac{N_{s} i_{s}}{\mathfrak{R}_{o}}-\frac{N_{p} i_{2}}{\mathfrak{R}_{o}+2 \mathfrak{R}_{c}} \cdot \frac{\Re_{c}}{\mathfrak{R}_{o}} \\
& \phi_{2}=-\frac{N_{p} i_{1}}{\mathfrak{R}_{o}+2 \mathfrak{R}_{c}} \cdot \frac{\mathfrak{R}_{c}}{\mathfrak{R}_{o}}+\frac{N_{s} i_{s}}{\mathfrak{R}_{o}}+\frac{N_{p} i_{2}}{\mathfrak{R}_{o}+2 \mathfrak{R}_{c}}\left(1+\frac{\mathfrak{R}_{c}}{\mathfrak{R}_{o}}\right) \\
& \phi_{c}=\frac{N_{p} i_{1}}{\mathfrak{R}_{o}+2 \mathfrak{R}_{c}}+\frac{N_{p} i_{2}}{\mathfrak{R}_{o}+2 \mathfrak{R}_{c}}
\end{aligned}
$$

Applying Faraday's Law to the four windings in the converter shown in figure 3 yields:

$N_{p} \frac{d \phi_{1}}{d t}=E-v_{C 2}$

$N_{p} \frac{d \phi_{2}}{d t}=E-v_{C 1}$

$N_{s} \frac{d \phi_{1}}{d t}-N_{s} \frac{d \phi_{2}}{d t}=v_{s}$

The currents in the two primary windings and the fluxes in the three core legs in the converter shown in figure 3 are, respectively, governed by the following equations:

$i_{1}=i_{\mathrm{Q} 2}+C_{r} \frac{d v_{\mathrm{C} 2}}{d t}$

$i_{2}=i_{Q 1}+C_{r} \frac{d v_{C 1}}{d t}$

$\phi_{\mathrm{c}}=\phi_{1}+\phi_{2}$

In order to obtain the equations of the derivatives of the converter instantaneous input and transformer secondary currents in the converter shown in figure 3 in the corresponding formats as equations (1) to (4), two inductance values can be defined as follows:

$$
\begin{aligned}
& \tilde{L}=\frac{N_{p}^{2}}{\Re_{o}+2 \Re_{c}} \\
& \tilde{\tilde{L}}=\frac{2 N_{s}^{2}}{\Re_{o}}
\end{aligned}
$$

Manipulations of equations (5) to (13) yield equation (4) and the following equations:

$$
\begin{aligned}
& \frac{d\left(i_{1}+i_{2}\right)}{d t}=\frac{1}{\tilde{L}}\left(2 E+K_{1} \frac{N_{p}}{N_{s}} v_{s}\right) \\
& \frac{d i_{s}}{d t}=K_{2} \frac{N_{p}}{N_{s}} \cdot \frac{E}{\tilde{L}}-\left[\frac{1}{\tilde{\tilde{L}}}+\left(\frac{N_{p}}{N_{s}}\right)^{2} \frac{1}{2 \tilde{L}}\right] v_{s}-\left(\frac{N_{p}}{N_{s}}\right)^{2} C_{r} \frac{d^{2} v_{s}}{d t^{2}}
\end{aligned}
$$

$$
\frac{d\left(i_{1}+i_{2}\right)}{d t}=\frac{2 E}{\tilde{L}}
$$

In equations (4) and (16) to (18), the coefficient $K_{j}= \pm 1$ depending on the specific switching state, where $j=1,2,3$. In State $1, Q_{1}$ is off and $Q_{2}$ is on. In this state, the additional circuit constraints are $v_{C 2}=0$ and $i_{Q 1}=0$. The current derivatives can be described by equations (16) and (17), where $K_{1}=-1$ and $K_{2}=+1$. In State 2, $Q_{1}$ and $Q_{2}$ are both on. In this state, the additional circuit constraints are $v_{C 1}=0$ and $v_{C 2}=0$. The current derivatives can be described by equations (18) and (4), where $K_{3}=-1$. In State 3, $Q_{1}$ is on and $Q_{2}$ is off. In this state, the additional circuit constraints are $v_{\mathrm{C} 1}=0$ and $i_{\mathrm{Q} 2}=0$. The current derivatives can be described by equations (16) and (17), where $K_{1}=+1$ and $K_{2}=-1$. In State $4, Q_{1}$ and $Q_{2}$ are both on. In this state, the additional circuit constraints are again $v_{C 1}=0$ and $v_{C 2}=0$. The current derivatives can be described by equations (18) and (4), where $K_{3}=+1$. Comparisons of equations (16) to (18), respectively, with equations (1) to (3) yield:

$$
\begin{aligned}
& L=\tilde{L}=\frac{N_{p}^{2}}{\mathfrak{R}_{o}+2 \mathfrak{R}_{c}} \\
& L_{m s}=\frac{1}{\frac{1}{\tilde{\tilde{L}}}-\left(\frac{N_{p}}{N_{s}}\right)^{2} \frac{1}{2 \tilde{L}}}=-\frac{N_{s}^{2}}{\mathfrak{R}_{c}}
\end{aligned}
$$

Equations (19) and (20) imply that the input inductances are related to the reluctances of both the outer and the centre core legs, and the magnetising inductance is inversely proportional to that of the centre core leg only. In this magnetic structure, the centre core leg can be gapped to store the energy in the input inductors. The outer core legs can also be gapped but this is not a must. If the centre core leg is the only gapped leg, the input inductances can be estimated to be inversely proportional to the reluctance of the centre core leg as $\Re_{c}>>\Re_{0}$ in this case. A bonus of gapping the centre core leg only is that it provides a close coupling for the two input inductor windings.

\section{RESONANT STATE ANALYSIS}

According to the magnetic circuit analysis in section 3 , the ZVS converter with the integrated magnetics shown in figure 3 can be modelled by that with discrete magnetics shown in figure 4 . To be close to the resonant capacitors, the resonant state analysis is conducted with the resonant inductance referred to the transformer primary side. A summary of the resonant state analysis within one complete switching period is provided in table 1 , where $L_{r}=N_{p}^{2} L_{r s} / N_{s}^{2}$. In the analysis, the input inductor and the output capacitor are assumed to be large enough that they can be respectively modelled by the current source $I_{0}=I_{I N} / 2$ and the voltage source $V_{d}=N_{p} V_{O} / 2 N_{s}$. The load condition is defined by $I_{0} Z_{0}=k V_{d}$. States (a) and (e) do not exist when $\Delta_{1}=0$. States (b) and (f) will be bypassed if the coefficient $\Delta_{1}$ is large enough and the 
Table 1: Resonant equations in the individual states.

\begin{tabular}{|c|c|c|c|}
\hline Resonant state & Circuit diagram & Resonant capacitor voltages and resonant inductor & ent \\
\hline $\begin{array}{l}\text { State (a) }\left(0 \leq t \leq t_{1}\right) \\
Q_{1} \text { turns off when } \\
i_{L r}=-\Delta_{1} I_{0}\end{array}$ & 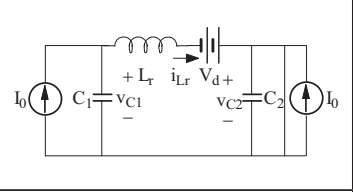 & $\begin{array}{l}v_{C 1}(t)=\left(1+\Delta_{1}\right) I_{0} Z_{0} \sin \left(\omega_{0} t\right)+V_{d} \cos \left(\omega_{0} t\right)-V_{d} \\
v_{C 2}(t)=0 \\
i_{L r}(t)=\left(V_{d} / Z_{0}\right) \sin \left(\omega_{0} t\right)-\left(1+\Delta_{1}\right) I_{0} \cos \left(\omega_{0} t\right)+I_{0}\end{array}$ & $\begin{array}{l}(21) \\
(22) \\
(23)\end{array}$ \\
\hline $\begin{array}{l}\text { State }(b)\left(t_{1} \leq t \leq t_{2}\right) \\
C_{1} \text { linearly charges }\end{array}$ & $\begin{array}{l}+L_{v_{C l}}^{+} \\
-L_{1}\end{array}$ & $\begin{array}{l}v_{C 1}(t)=\left(I_{0} / C_{r}\right)\left(t-t_{1}\right)+v_{C 1}\left(t_{1}\right) \\
v_{C 2}(t)=0 \\
i_{L r}(t)=0\end{array}$ & $\begin{array}{l}(24) \\
(22) \\
(25)\end{array}$ \\
\hline $\begin{array}{l}\text { State }(\mathrm{c})\left(t_{2} \leq t \leq t_{3}\right) \\
C_{1} \text { resonates with } \\
L_{r}\end{array}$ & & $\begin{array}{l}v_{C 1}(t)=I_{0} Z_{0} \sin \omega_{0}\left(t-t_{2}\right)+\left[v_{C 1}\left(t_{2}\right)-V_{d}\right] \cos \omega_{0}\left(t-t_{2}\right)+V_{d} \\
v_{C 2}(t)=0 \\
i_{L r}(t)=\left[\left(v_{C 1}\left(t_{2}\right)-V_{d} / Z_{0}\right] \sin \omega_{0}\left(t-t_{2}\right)-I_{0} \cos \omega_{0}\left(t-t_{2}\right)+I_{0}\right.\end{array}$ & $\begin{array}{l}(26) \\
(22) \\
(27)\end{array}$ \\
\hline $\begin{array}{l}\text { State }(\mathrm{d})\left(t_{3} \leq t \leq t_{4}\right) \\
Q_{1} \text { turns on when } \\
v_{C 1}=0\end{array}$ & $+L_{1}$ & $\begin{array}{l}v_{\mathrm{C} 1}(t)=0 \\
v_{\mathrm{C} 2}(t)=0 \\
i_{L r}(t)=i_{L r}\left(t_{3}\right)-\left(V_{d} / L_{r}\right)\left(t-t_{3}\right)\end{array}$ & $\begin{array}{l}(28) \\
(22) \\
(29)\end{array}$ \\
\hline $\begin{array}{l}\text { State }(\mathrm{e})\left(t_{4} \leq t \leq t_{5}\right) \\
Q_{2} \text { turns off when } \\
i_{L r}=\Delta_{1} I_{0}\end{array}$ & $\mathrm{r}_{0} \mathrm{C}$ & $\begin{array}{l}v_{C 1}(t)=0 \\
v_{C 2}(t)=\left(1+\Delta_{1}\right) I_{0} Z_{0} \sin \omega_{0}\left(t-t_{4}\right)+V_{d} \cos \omega_{0}\left(t-t_{4}\right)-V_{d} \\
i_{L r}(t)=-\left(V_{d} / Z_{0}\right) \sin \omega_{0}\left(t-t_{4}\right)+\left(1+\Delta_{1}\right) I_{0} \cos \omega_{0}\left(t-t_{4}\right)-I_{0}\end{array}$ & $\begin{array}{l}(28) \\
(30) \\
(31)\end{array}$ \\
\hline $\begin{array}{l}\text { State }(\mathrm{f})\left(t_{5} \leq t \leq t_{6}\right) \\
C_{2} \text { linearly charges }\end{array}$ & +1 & $\begin{array}{l}v_{C 1}(t)=0 \\
v_{C 2}(t)=\left(I_{0} / C_{r}\right)\left(t-t_{5}\right)+v_{C 2}\left(t_{5}\right) \\
i_{L r}(t)=0\end{array}$ & $\begin{array}{l}(28) \\
(32) \\
(25)\end{array}$ \\
\hline $\begin{array}{l}\text { State }(\mathrm{g})\left(t_{6} \leq t \leq t_{7}\right) \\
C_{2} \text { resonates with } L_{r}\end{array}$ & 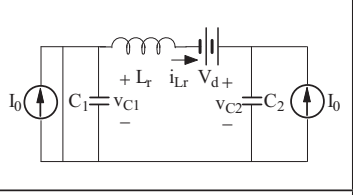 & $\begin{array}{l}v_{C 1}(t)=0 \\
v_{C 2}(t)=I_{0} Z_{0} \sin \omega_{0}\left(t-t_{6}\right)+\left[v_{C 2}\left(t_{6}\right)-V_{d}\right] \cos \omega_{0}\left(t-t_{6}\right)+V_{d} \\
i_{L r}(t)=-\left[\left(v_{C 2}\left(t_{6}\right)-V_{d} / Z_{0}\right] \sin \omega_{0}\left(t-t_{6}\right)-I_{0} \cos \omega_{0}\left(t-t_{6}\right)+I_{0}\right.\end{array}$ & $\begin{array}{l}(28) \\
(33) \\
(34)\end{array}$ \\
\hline $\begin{array}{l}\text { State }(h)\left(t_{7} \leq t \leq t_{8}\right) \\
Q_{2} \text { turns on when } \\
v_{C 2}=0\end{array}$ & 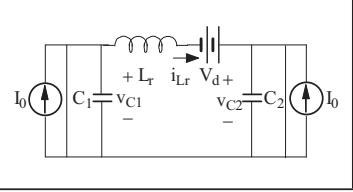 & $\begin{array}{l}v_{C 1}(t)=0 \\
v_{C 2}(t)=0 \\
i_{L r}(t)=i_{L r}\left(t_{7}\right)+\left(V_{d} / L_{r}\right)\left(t-t_{7}\right)\end{array}$ & $\begin{array}{l}(28) \\
(22) \\
(35)\end{array}$ \\
\hline
\end{tabular}

capacitor voltages $v_{C 1}$ and $v_{C 2}$ is higher than $V_{d}$ at the end of States (a) and (e).

\section{THEORETICAL AND EXPERIMENTAL WAVEFORMS}

In order to verify the theoretical analysis, a prototype converter with $20 \mathrm{~V}$ input, $340 \mathrm{~V}$ output and $100 \mathrm{~W}$ power rating was built in the laboratory as shown in figure 6. The parameters of the selected operating point are listed as follows:

- $k=1.1, \Delta_{1}=0$ and $V_{d} / E=2.15$.

- $L_{r}=2.80 \mu \mathrm{H}$ and $C_{r}=7.85 \mathrm{nF}$.

- Device switching frequency is $500 \mathrm{kHz}$ or the converter switching frequency is $1 \mathrm{MHz}$.

- Switching duty ratio is $61.6 \%$.

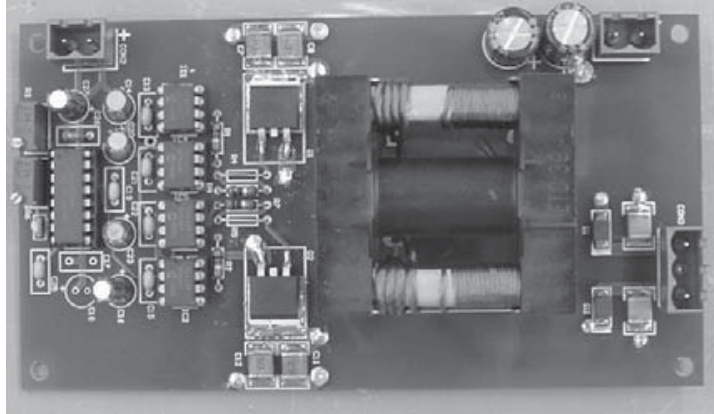

Figure 6: Photo of the prototype converter.

The theoretical waveforms can be plotted using equations (21) to (35) for the selected operating conditions and are shown in figure 7 . In the hardware implementation of the isolated ZVS two-inductor boost converter with the integrated magnetic structure, the following main components are used: 

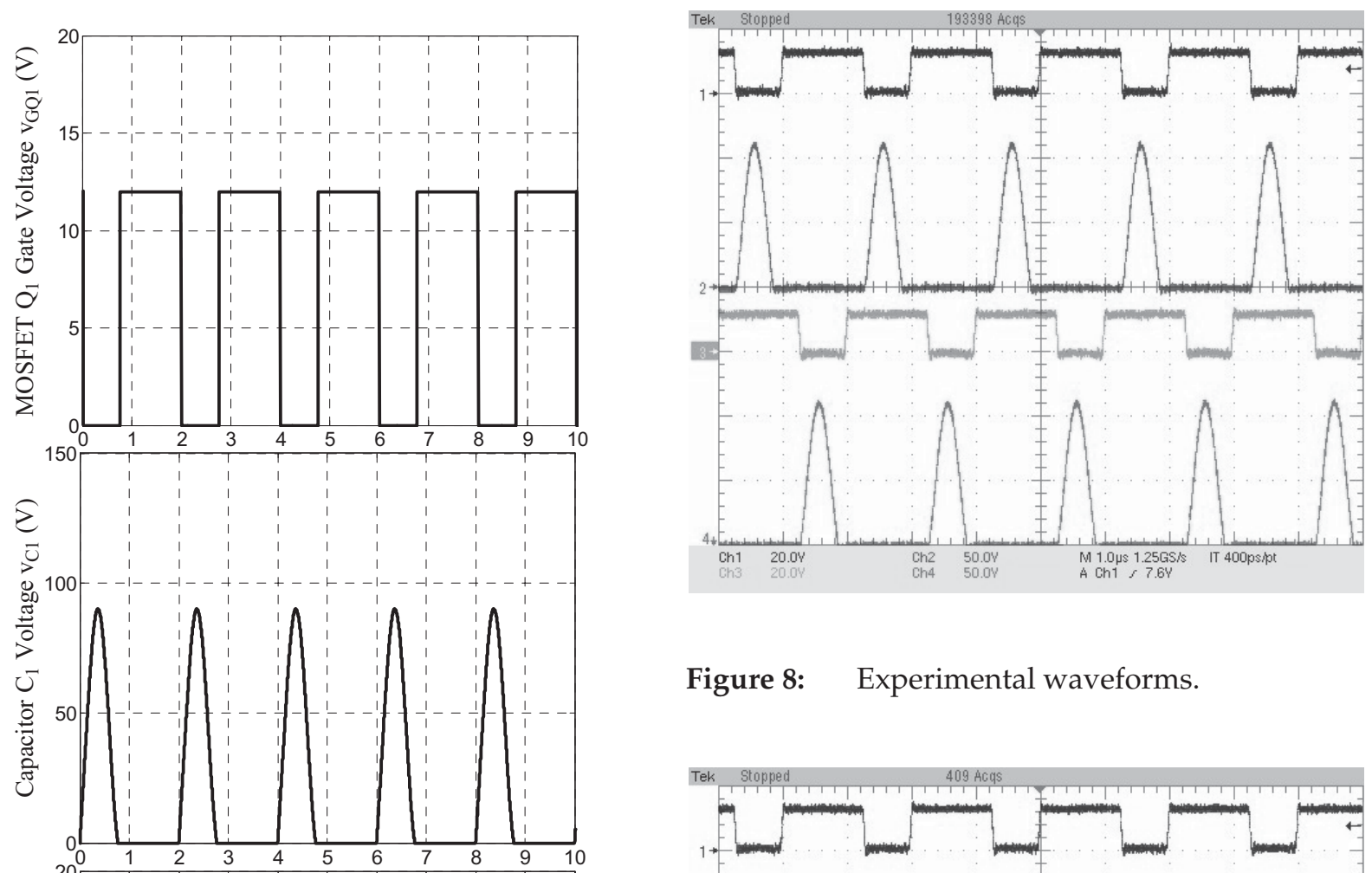

Figure 8: Experimental waveforms.
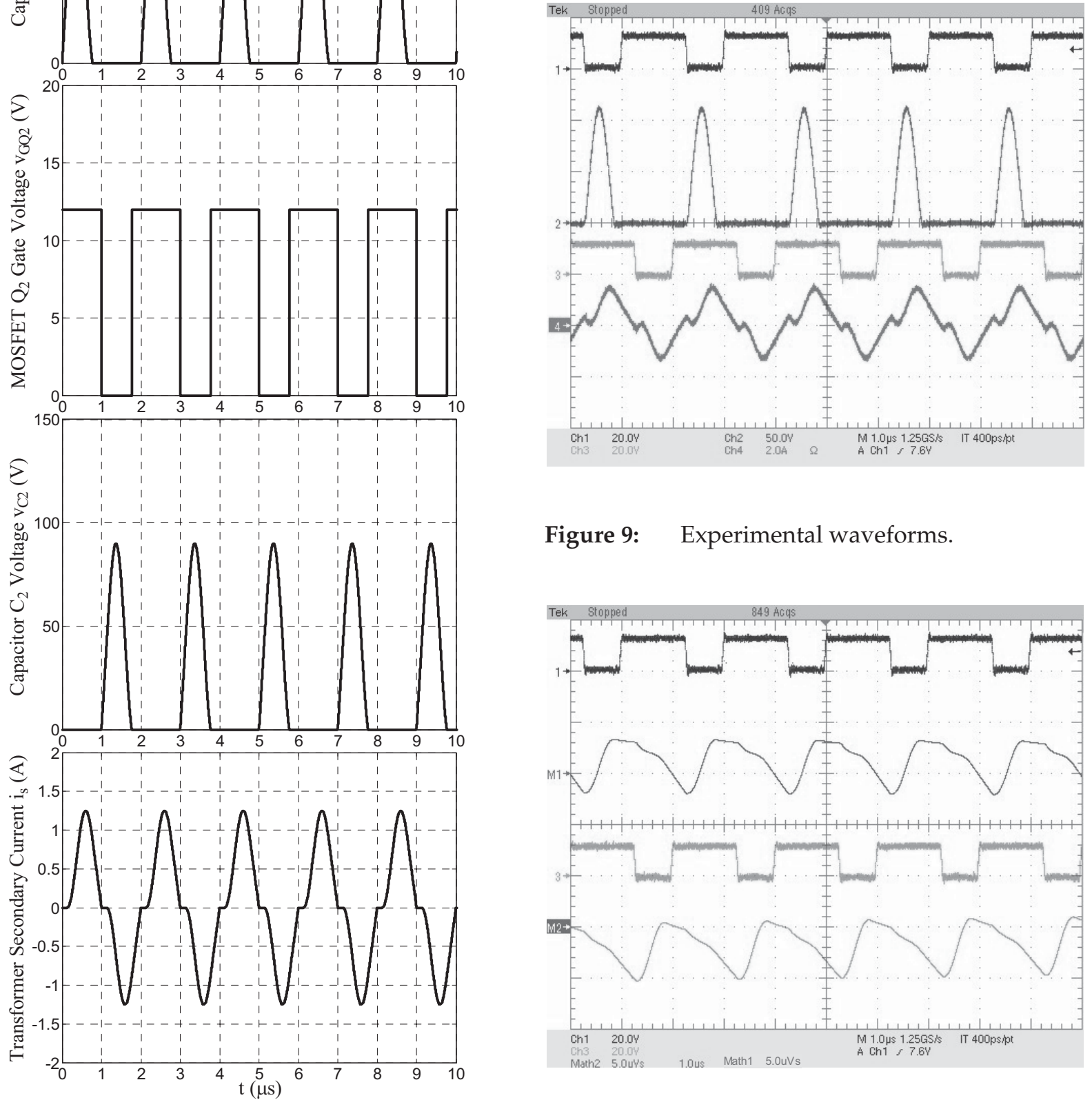

Figure 9: Experimental waveforms.

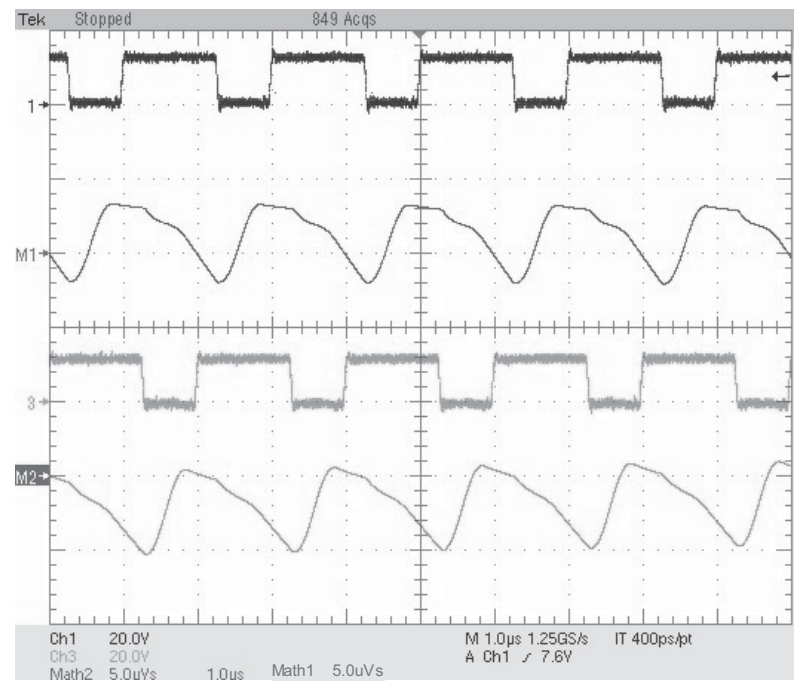

Figure 7: Theoretical waveforms.

Figure 10: Experimental waveforms. 
- Integrated magnetic structure - core type Ferroxube ETD39 with a $0.5 \mathrm{~mm}$ air gap in the centre core leg, minimum cross section area $123 \mathrm{~mm}^{2}$ (Ferroxcube, 2004), ferrite grade 3F3, primary winding $N_{p}=4$ turns, secondary winding $N_{s}=16$ turns, leakage inductance reflected to the top and the bottom primary windings are, respectively, $2.73 \mu \mathrm{H}$ and $2.69 \mu \mathrm{H}$.

- Additional resonant capacitors - Cornell Dubilier surface mount mica capacitor MC22FA202J and MC22FD102J, $2 \mathrm{nF}$ and $1 \mathrm{nF}$, three $2 \mathrm{nF}$ and one $1 \mathrm{nF}$ capacitors are used in parallel with each MOSFET.

- MOSFETs $Q_{1}$ and $Q_{2}$ - Vishay SUM85N15-19, $V_{D S}=150 \mathrm{~V}, I_{D}=85 \mathrm{~A}, R_{D S(o n)}=0.019 \Omega, C_{\text {oss }}=0.530 \mathrm{nF}$.

- Diodes $D_{1}$ and $D_{2}-$ ST STTA106U, $I_{F}=1.0 \mathrm{~A}$, $V_{\text {RRM }}=600 \mathrm{~V}, V_{F}=1.5 \mathrm{~V}$.

- Capacitors $C_{3}$ and $C_{4}$-MurataElectronics multilayer ceramic chip capacitors GRM55DR72E105KW01L, $1 \mu \mathrm{F}$, rated DC voltage $250 \mathrm{~V}$.

\section{CONCLUSIONS}

This paper studies the isolated ZVS two-inductor boost converter with two coupled input inductors and one magnetic core. This topology operates in the same way as the isolated ZVS two-inductor boost converter with an auxiliary transformer but reduces the seven copper winding and five magnetic core components to a single core with four copper windings. The analysis of the new converter can be performed with its equivalent model with discrete magnetics. The theoretical and the experimental waveforms of a prototype $1 \mathrm{MHz} 100 \mathrm{~W}$ converter are provided at the end of the paper to verify the theoretical analysis.

\section{REFERENCES}

Bloom, G. 2003, “Multi-chambered planar magnetics blends inductors and transformers", Power Electronics Technology, Vol. 29, No. 4, April, pp. 22-34.

Bloom, G. \& Severns, R. 1984, “The generalized use of integrated magnetics and zero-ripple techniques in switchmode power converters", Proc. IEEE PESC, pp. 15-33.

Chen, W. 1998, "Low voltage high current power conversion with integrated magnetics", PhD
Dissertation, Virginia Polytechnic Institute and State University, USA.

Ferroxcube, 2004, "ETD39/20/13 Datasheet", September, www.ferroxcube.com/prod/assets/ etd39.pdf.

Gao, X. \& Ayyannar, R. 2004, “A novel buck-cascaded two-inductor boost converter with integrated magnetic", in Proc. IEEE INTELEC, pp. 190-197.

Jang, Y. \& Jovanovic, M. M. 2001, “Two-inductor boost converter", U.S. Patent 6239 584, 29 May.

Jang, Y. \& Jovanovic, M. M. 2002, “New two-inductor boost converter with auxiliary transformer", in Proc. IEEE APEC, pp. 654-660; also IEEE Trans. Power Electron., Vol. 19, No. 1, January, 2004, pp. 169-175.

Jang, Y., Jovanovic, M. M. \& Hu, Y. 2005, “Nonisolated two-inductor boost converter with improved EMI performance", in Proc. IEEE INTELEC, pp. 491-496.

Li, Q. \& Wolfs, P. 2005a, "A comparison of three magnetics integration solutions for the two-inductor boost converter", in Proc. Australasian Universities Power Engineering Conference, pp. 629-634.

Li, Q. \& Wolfs, P. 2005b, "Analysis, design and experimentation of a zero-voltage switching twoinductor boost converter with integrated magnetics", in Proc. IEEE PESC, pp. 985-990.

Wolfs, P. J. 1993, “A current-sourced dc-dc converter derived via the duality principle from the half-bridge converter", IEEE Trans. Ind. Electron., Vol. 40, No. 1, February, pp. 139-144.

Wolfs, P. \& Li, Q. 2002, “An analysis of a resonant half bridge dual converter operating in continuous and discontinuous modes", in Proc. IEEE PESC, pp.1313-1318.

Yan, L. \& Lehman, B. 2003, "Isolated two-inductor boost converter with one magnetic core", in Proc. IEEE APEC, pp. 879-885.

Yan, L. \& Lehman, B. 2005, "An integrated magnetic isolated two-inductor boost converter: analysis, design and experimentation", IEEE Trans. Power Electron., Vol. 20, No. 2, March, pp. 332-342. 


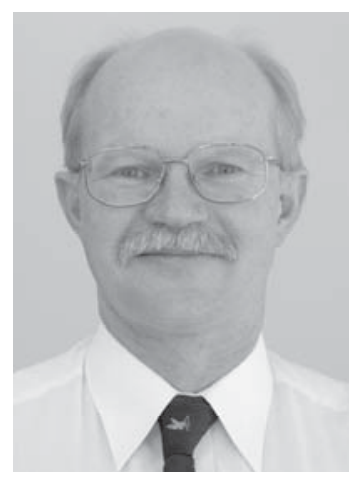

\section{PETER WOLFS}

Prof Peter Wolfs graduated from the Capricornia Institute of Advanced Education in 1980 with a Bachelor of Engineering Degree. He subsequently secured a Master of Engineering degree with the Philips International Institute in the Netherlands in 1981 and a PhD degree at the University of Queensland in 1992. He currently holds the Western Power Chair in Electrical Engineering at Curtin University of Technology, Perth. His special fields of interest include Smart Grid technology, rural and renewable energy supply, and electric, solar and hybrid electric vehicles. Peter is Senior Member of IEEE, a Fellow of Engineers Australia, and a Registered Professional Engineer in the State of Queensland.

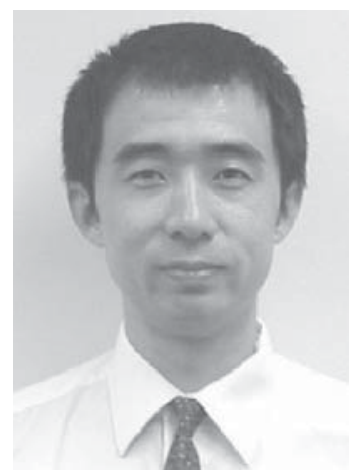

\section{QUAN LI}

Dr Quan Li received his BEng degree in electrical engineering from Tsinghua University, Beijing, China, in 1997, and MEng and PhD degrees from Central Queensland University, Rockhampton, Australia, in 2002 and 2006, respectively. He is currently working as the Regional Asset Engineer at Ergon Energy. His research interests include high-frequency converters, renewable energy applications and power system reliability. He is a member of Engineers Australia. 